\title{
ANÁLISE TÉCNICA E ECONÔMICA DAS ETAPAS DE PRODUÇÃo DE MUDAS DE EUCALIPTO
}

\author{
Danilo Simões ${ }^{1}$, Magali Ribeiro da Silva ${ }^{2}$
}

(recebido: 4 de agosto de 2009; aceito: 28 de maio de 2010)

\begin{abstract}
RESUMO: Com o objetivo de estimar os rendimentos operacionais e custos de produção de mudas de Eucalyptus grandis por meio de propagação vegetativa, conduziu-se o estudo em um viveiro de produção de mudas, pertencente a uma empresa florestal de grande porte, localizada no Estado de São Paulo. A análise técnica englobou um estudo de tempos e movimentos pelo método de tempo contínuo. A análise econômica ponderou todos os custos operacionais e de produção. Os resultados obtidos evidenciaram que as despesas com pessoal são as que mais oneram o custo da produção de mudas de eucalipto. Os coeficientes técnicos de cada etapa de produção devem ser administrados no sentido de estabelecer o valor ótimo da eficiência e do rendimento operacional, tornando-as economicamente viáveis.
\end{abstract}

Palavras-chave: Viveiro florestal, propagação vegetativa, produtividade.

\section{TECHNICAL AND ECONOMIC ANALYSIS OF THE STAGES OF EUCALYPTUS SEEDLINGS PRODUCTION}

ABSTRACT: The aim of this study was to estimate the operating performance and production costs of Eucalyptus grandis seedlings by vegetative propagation, the study was carried out on a nursery, which belongs to a great forest company located in São Paulo state, Brazil. The technical analysis included a study of times and movements by continuous time method. The economic analysis considered all operating and production costs. The results showed that the expenditures with labor costs are the most significant in the final cost of eucalyptus seedling production. The technical coefficients of each production stage must be administered in a way to establish the optimal value of efficiency and operating performance, making them economically viable.

Key words: Forest nursery, vegetative propagation, productivity.

\section{INTRODUÇÃo}

No início dos plantios de eucalipto em larga escala, as mudas eram produzidas por meio de sementes não melhoradas, o que muitas vezes resultava em má qualidade dos povoamentos, em razão da desuniformidade do material (FREITAS et al., 2006).

A produção de eucalipto por propagação vegetativa iniciou-se em 1975, na República Popular do Congo (DEWAULLE et al., 1983), e foi introduzida no Brasil ainda no final da década de 70 (CAMPINHOS \& IKEMORI, 1983), proporcionando vantagens como a manutenção de características genéticas pouco herdáveis (PENCHEL et al., 1995).

A produção comercial de mudas de eucalipto na maioria das empresas florestais é realizada em sua quase totalidade por meio de propagação vegetativa, permitindo uma melhoria na produtividade e qualidade das florestas, garantindo vantagens como uniformidade dos povoamentos, melhor adaptação dos clones às condições locais e aumento na produtividade (XAVIER \& COMÉRIO, 1996).
Segundo Gonçalves \& Poggiani (1996), a produção de mudas florestais, em quantidade e qualidade, é uma das fases mais importantes para o estabelecimento de povoamentos florestais, com grande repercussão sobre a produtividade. Portanto, muitos trabalhos têm sido desenvolvidos no sentido de melhorar a qualidade e reduzir os custos de produção de mudas.

Diante disso, os rendimentos operacionais aliados aos custos de produção de mudas florestais se tornaram imperativos no planejamento e execução de todas as etapas que compõem a operação. Portanto, a maximização operacional e a minimização dos custos de produção, incorporados aos custos de investimentos e de receitas futuras, são de suma importância nas tomadas de decisões, o que as tornam mais seguras economicamente.

Em decorrência da necessidade constante da redução dos custos de produção, o estudo foi conduzido com o objetivo de estimar os rendimentos operacionais e custos de produção de mudas de eucalipto por propagação vegetativa.

\footnotetext{
${ }^{1}$ Administrador de Empresas, Doutorando em Agronomia - Departamento de Recursos Naturais/Ciências Florestais - Faculdade de Ciências Agronômicas/FCA - Universidade Estadual Paulista/UNESP - Cx. P. 237 - 18610-307 - Botucatu, SP - simoesdanilo@yahoo.com.br ${ }^{2}$ Engenheira Florestal, Professora Dra. em Agronomia - Departamento de Recursos Naturais/Ciências Florestais - Faculdade de Ciências Agronômicas/FCA - Universidade Estadual Paulista/UNESP - Cx. P. 237 - 18610-307 - Botucatu, SP - magaliribeiro@fca.unesp.br
} 


\section{MATERIAL E MÉTODOS}

\section{1 Área experimental}

O estudo foi desenvolvido num viveiro de produção de mudas de Eucalyptus grandis por meio de propagação vegetativa, tipo setorizado, pertencente a uma empresa florestal de grande porte e tradicional do setor de produção de painéis de madeira, localizada no Estado de São Paulo, que possui mão-de-obra própria e capacidade produtiva para 20 milhões de mudas ao ano. Todas as mudas de eucalipto produzidas eram destinadas a produção própria de florestas, para o suprimento da fibra de madeira às atividades industriais da empresa onde foi realizado o estudo.

A coleta dos dados foi efetuada entre os meses de outubro e dezembro de 2008, durante o turno de trabalho compreendido entre 7 e 17 horas. As condições climáticas se mantiveram sem alterações, com o céu encoberto e com períodos de sol durante o estudo.

\subsection{Etapas de produção}

As etapas de produção avaliadas foram aquelas diretamente abrangidas no processo de produção de mudas, sendo essas compreendidas por operações manuais e semimecanizadas descritas na Tabela 1.

\subsection{Coleta de dados}

O número de ciclos operacionais foi estimado por meio da metodologia proposta por Barnes (1968). Por intermédio de um estudo-piloto foi estimado o número mínimo de ciclos operacionais para um erro de amostragem admissível fixado em 5\%, a 95\% de probabilidade (Equação 1).

$$
n \geq \frac{t^{2} \times C V^{2}}{E^{2}}
$$

onde,

n - número mínimo de ciclos operacionais necessários;

$\mathrm{t}$ - valor de t, Student, no nível de probabilidade desejado e (n-1) graus de liberdade;

$\mathrm{CV}$ - coeficiente de variação (\%);

E - erro admissível (\%).

\subsection{Estudo de tempos e movimentos}

A coleta dos dados para estimar os rendimentos operacionais foi realizada empregando-se o método de cronometragem de tempo contínuo. Esse método caracteriza-se pela medição do tempo sem detenção do cronômetro, isto é, de forma contínua.

Foram utilizados cronômetros digitais da marca Technos para obtenção dos dados. Esses cronômetros possuem graduação até a escala de milésimos, porém ponderou-se até a escala de segundos, em razão da facilidade do registro dos dados. A seleção dos trabalhadores amostrados foi inteiramente casualisada.

A operação de produção de mudas de eucalipto foi subdividida em atividades parciais e esta classificada em

Tabela 1 - Descrição das etapas de produção de mudas de eucalipto.

Table 1 -Description of the stages of eucalyptus seedling production.

\begin{tabular}{ll}
\hline Etapas de produção & \multicolumn{1}{c}{ Atividades } \\
\hline Desinfecção de tubetes & $\begin{array}{l}\text { A etapa de desinfecção foi realizada por intermédio da imersão dos tubetes em água durante } 3 \\
\text { minutos, a uma temperatura de aproximadamente } 80^{\circ} \mathrm{C} .\end{array}$ \\
\hline $\begin{array}{l}\text { Coleta de estacas e } \\
\text { estaqueamento }\end{array}$ & $\begin{array}{l}\text { A coleta de estacas foi realizada no jardim clonal localizado no próprio viveiro florestal. } \\
\text { Posteriormente, iniciava-se o processo de estaqueamento, por meio da inserção das estacas nos } \\
\text { tubetes com substrato. }\end{array}$ \\
\hline Seleção e alternagem & $\begin{array}{l}\text { Com a seleção e alternagem das mudas de eucalipto objetivou-se retornar às mudas menores à } \\
\text { casa de sombra, para que pudessem obter um maior comprimento do caule e sistema radicular e, } \\
\text { as mudas maiores eram levadas aos canteiros a pleno sol. }\end{array}$ \\
\hline Expedição de mudas & $\begin{array}{l}\text { As mudas de eucalipto que estavam nas bandejas a pleno sol eram selecionadas e alocadas em } \\
\text { caixas plásticas utilizadas para o transporte até o campo. }\end{array}$ \\
\hline Preparo do substrato & $\begin{array}{l}\text { O preparo do substrato consistiu na mistura de um substrato comercial com fibra de coco e com a } \\
\text { adição de superfosfato simples, os quais eram depositados num misturador automatizado. }\end{array}$ \\
\hline Enchimento de tubetes & $\begin{array}{l}\text { Os tubetes vazios eram acondicionados nas bandejas, as quais deslocavam sobre uma esteira } \\
\text { rolante até o ponto de enchimento com o substrato, o qual era realizado por gravidade. } \\
\text { Posteriormente, essas bandejas passavam por uma mesa de vibração, cuja função era realizar a } \\
\text { compactação do substrato nos tubetes. }\end{array}$ \\
\hline
\end{tabular}

Cerne, Lavras, v. 16, n. 3, p. 359-366, jul./set. 2010 
atividades efetivas e atividades gerais, de acordo com a metodologia proposta por Barnes (1977).

As atividades efetivas (AE) englobaram todos os movimentos planejados que ocorrem repetitivamente durante o decurso do trabalho e que resultam em produção ou são, necessárias para a realização do trabalho. As atividades efetivas indicam o grau de eficiência, ou efetividade. As atividades gerais (AG) são todas aquelas que ocorrem repetidamente, ou casualmente, durante o decurso do trabalho, mas que não resultam em produção. A cada atividade parcial corresponde o tempo dispendido na sua realização.

\subsection{Eficiência operacional}

A eficiência operacional foi definida como o percentual do tempo das atividades efetivas, ou seja, engloba todas as atividades parciais que ocorrem repetitivamente durante o decurso do trabalho e que resultam em produção (Equação 2).

$$
E_{o}=\frac{H E \times 100}{H T}
$$

onde,

$\mathrm{E}_{\mathrm{o}}=$ eficiência operacional (\%);

$\mathrm{HE}=$ tempo efetivo de trabalho (horas);

$\mathrm{HT}=$ tempo total de trabalho (horas).

\subsection{Rendimentos operacionais}

Os rendimentos operacionais foram apresentados em hora-homem por mil (H.H.mil ${ }^{-1}$ ), ou seja, tempo dispendido para um homem executar sua tarefa, sendo essa mensurada em mil tubetes, estacas ou mudas de eucalipto, de acordo com as variações de cada etapa de produção (Equação 3).

$$
R=\frac{T}{n} \times 1000
$$

onde,

$\mathrm{R}$ - rendimento operacional médio (H.H.mil ${ }^{-1}$ );

$\mathrm{T}$ - tempo em horas (h);

$\mathrm{N}$ - número de tubetes, estacas ou mudas de eucalipto.

\subsection{Determinação dos custos de produção}

Os custos operacionais foram fornecidos pela empresa onde foi realizado o estudo e foram expressos em dólar dos Estados Unidos (US\$). Foi considerado como taxa de câmbio o preço da moeda estrangeira medido em unidades e frações da moeda nacional, que era de $\mathrm{R} \$ 1,9143$ de 30/09/2.008.

Os custos operacionais foram classificados de acordo com o percentual que cada etapa representa na operação de produção de mudas de eucalipto. A estimativa do custo de produção foi obtida por meio da Equação 4. Os custos que incidem diretamente sobre as despesas com pessoal foram decorrentes do somatório de mão-de-obra dos trabalhadores, encargos sociais, materiais de segurança, administração de operações e serviços de terceiros, dividindo-os pelos recursos humanos dispendidos.

$C p=\frac{(C o \times P e)}{1000}$

onde,

$\mathrm{Cp}$ - custo de produção de mudas (US\$.mil-1);

Co - custo operacional (US\$);

$\mathrm{Pe}$ - percentual da etapa de produção de mudas (\%).

A partir dos custos por etapa de produção, foi possível fazer a análise de Pareto, a qual se apresenta como uma ferramenta para identificar quais foram as etapas responsáveis pela maior parcela dos custos de produção e quais devem ser priorizadas na adoção de melhorias.

\section{RESULTADOS E DISCUSSÃO}

Para todas as etapas estudadas, foi estabelecido um erro de amostragem admissível em 5\%. O número mínimo de ciclos operacionais fixados como necessários e o número de ciclos observados estão descritos na Tabela 2.

\subsection{Estudo de tempos e movimentos}

Os resultados relativos aos tempos consumidos nas etapas de produção de mudas são apresentados na Tabela 3, sendo esses referentes às atividades parciais efetivas. $\mathrm{O}$ problema de avaliação do tempo foi discorrido por Becker (1965), Harrison \& Quarmby (1972) e Steiner (1959), sem, contudo, chegarem a um consenso sobre qual a melhor metodologia para avaliá-lo. Entretanto, Barnes (1977) assegura ser possível a determinação do tempo-padrão para a realização de uma tarefa específica.

Quando comparados os tempos dispendidos para o cumprimento de cada etapa de produção de mudas de eucalipto, de acordo com o total, observa-se, na Figura 1, que a etapa que consumiu mais tempo para ser realizada foi a coleta de estacas e estaqueamento, a qual representou $59,27 \%$ do tempo total, seguida da

Cerne, Lavras, v. 16, n. 3, p. 359-366, jul./set. 2010 
Tabela 2 - Número de ciclos necessários e observados.

Table 2 - Number of required and observed cycles.

\begin{tabular}{lcc}
\hline Etapas de produção & Ciclos mínimos & Ciclos observados \\
\hline Desinfecção de tubetes & 249 & 318 \\
Coleta de estacas e estaqueamento & 293 & 337 \\
Seleção e alternagem & 1.543 & 1.754 \\
Expedição de mudas & 2.152 & 2.419 \\
Preparo do substrato & 399 & 466 \\
Enchimento de tubetes & 605 & 680 \\
\hline
\end{tabular}

Tabela 3 - Tempos consumidos das atividades efetivas desenvolvidas da produção de mudas de eucalipto por propagação vegetativa.

Table 3 - Estimates of the times of the different effective activities of eucalyptus seedling production through vegetative propagation.

\begin{tabular}{|c|c|c|c|}
\hline Etapas de produção & Tempo total médio & Produção & Unidades \\
\hline Desinfecção de tubetes & $27 \mathrm{~h} 15^{\prime} 57^{\prime \prime}$ & 74.976 & tubetes \\
\hline $\begin{array}{l}\text { Coleta de estacas e } \\
\text { estaqueamento }\end{array}$ & $33 \mathrm{~h} 28^{\prime} 54^{\prime \prime}$ & 16.104 & estacas \\
\hline Seleção e alternagem & 30h 06'32” & 89.760 & mudas \\
\hline Expedição de mudas & $32 \mathrm{~h} 59^{\prime} 06^{\prime \prime}$ & 49.770 & mudas \\
\hline Preparo do substrato & $7 \mathrm{~h} 29^{\prime} 44^{\prime \prime}$ & 457.580 & tubetes \\
\hline Enchimento de tubetes & $7 \mathrm{~h} 48^{\prime} 47^{\prime \prime}$ & 352.352 & tubetes \\
\hline
\end{tabular}

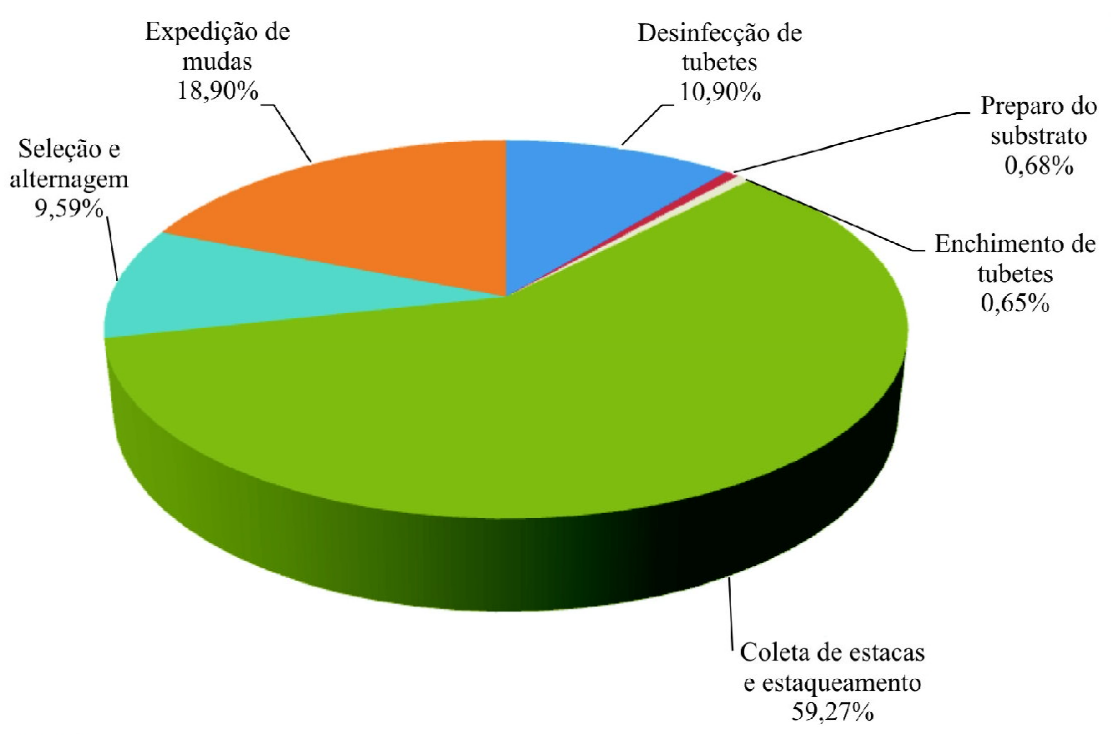

Figura 1 - Percentuais de tempos dispendidos nas etapas de produção de mudas de eucalipto.

Figure 1 - Time percentage used in the production stages of eucalyptus seedlings.

Cerne, Lavras, v. 16, n. 3, p. 359-366, jul./set. 2010 
expedição de mudas, realizada em 18,90\% do tempo total. A desinfecção de tubetes foi realizada em 10,90\% do tempo total. A etapa de seleção e alternagem foi conduzida com $9,59 \%$ e, o enchimento de tubetes e preparo do substrato, contíguas consumiram $1,34 \%$ do tempo total da produção de mudas.

\subsection{Produtividade}

Por meio da obtenção dos percentuais de produtividade, foi possível detectar que algumas etapas podem implicar de forma antieconômica no processo de produção. Dentre essas, estão as etapas de preparo do substrato e enchimento de tubetes que resultaram em uma baixa eficiência operacional infligida por problemas organizacionais (Tabela 4). Segundo Bruzzi (2002), para se obter uniformidade no processo de produção, sem a ocorrência de problemas e com o propósito de impetrar maior qualidade e produtividade, se faz necessário um processo controlado e planejado. Dinsmore \& Silveira Neto (2004) afirmam que o gerenciamento da integração consiste em fazer com que todas as etapas de produção envolvidas tenham uma interação contínua, fazendo com que tudo labore bem ao mesmo tempo.

\subsection{Rendimento operacional}

$\mathrm{Na}$ Tabela 5, podem ser observados os rendimentos operacionais por tubetes, estacas ou mudas de eucalipto e a participação percentual acumulado para cada etapa de produção. De acordo com Rezende \& Silva (1997), o sucesso de um projeto depende da sua prévia avaliação, que resulta em racionalização das atividades para maximizar a produtividade e minimizar os custos de produção. Assim sendo, a necessidade de avaliar um projeto que engloba várias etapas de execução, é de extrema importância para o profissional ligado à área florestal.

Entre as etapas de produção estudadas, a mais representativa foi a coleta de estacas e estaqueamento, a qual englobou a confecção das estacas e o estaqueamento por apresentar o menor rendimento operacional. Para essa etapa, foi necessário despender aproximadamente $2 / 3$ do tempo de trabalho para a operação fim.

Tabela 4 - Eficiência operacional das etapas de produção de mudas de eucalipto.

Table 4-Operational efficiency of the stages of eucalyptus seedling production.

\begin{tabular}{lc}
\hline Etapas de produção & Eficiência operacional $(\%)$ \\
\hline Desinfecção de tubetes & 85,58 \\
Coleta de estacas e estaqueamento & 77,12 \\
Seleção e alternagem & 84,10 \\
Expedição de mudas & 81,06 \\
Preparo do substrato & 29,76 \\
Enchimento de tubetes & 29,92 \\
\hline
\end{tabular}

Tabela 5 - Rendimentos operacionais e percentuais acumulado por etapa de produção.

Table 5 - Operational performance and accumulated percentage per production stage.

\begin{tabular}{lcccc}
\hline \multirow{2}{*}{ Etapas de produção } & \multicolumn{2}{c}{ Rendimento operacional } & \multicolumn{2}{c}{ Participação $(\%)$} \\
\cline { 2 - 5 } & $\left(\right.$ H.H.mil $\left.{ }^{-1}\right)$ & Acumulado & Etapa & Acumulado \\
\hline Coleta de estacas e estaqueamento & 2,082 & 2,08 & 59,27 & 59,27 \\
Expedição de mudas & 0,664 & 2,75 & 18,90 & 78,17 \\
Desinfecção de tubetes & 0,383 & 3,13 & 10,90 & 89,07 \\
Seleção e alternagem & 0,337 & 3,47 & 9,59 & 98,66 \\
Enchimento tubetes & 0,023 & 3,49 & 0,66 & 99,32 \\
Preparo do substrato & 0,024 & 3,51 & 0,68 & 100,00 \\
\hline
\end{tabular}




\subsection{Custo de produção de mudas}

Um bom gerenciamento dos custos institui os processos indispensáveis para garantir que um projeto proporcione a possibilidade de melhorias e desenvolvimento dentro dos orçamentos préestabelecidos.

De acordo com Silva et al. (2005), os custos de produção de mudas, consiste na realização de várias suboperações, que incluem desde a coleta ou aquisição de sementes, ou coleta de estacas, até a obtenção das mudas prontas para o plantio. Assim sendo, por meio da estimativa dos rendimentos operacionais e participação percentual por etapa de produção no custo total de produção de mudas de eucalipto, foi possível definir os custos de cada uma delas, de forma a captar todos os itens que a compõem. Os custos que advêm das despesas com pessoal representaram $64,92 \%$ do custo total de produção de mudas, conforme pode ser observado na Tabela 6.
Após os cálculos da participação percentual por etapa de produção, foi possível estimar os custos de produção de mudas, conforme a distribuição apresentada na Tabela 7. O custo total das etapas que englobam a produção de mudas de eucalipto foi de US\$ 130.97 por milheiro produzido, o qual resultou num custo por muda de eucalipto produzida de US\$ 0.13 .

Como pode ser observado no gráfico de Pareto (Figura 2), os recursos financeiros foram concentrados na etapa de coleta e estaqueamento, a qual representa $59,28 \%$ dos custos de produção. Portanto, para que essa etapa de produção não se torne antieconômica para a empresa, deve haver um empenho na melhoria da produtividade, haja vista que o percentual obtido foi de aproximadamente $70 \%$.

Esse comedimento deve ser aplicado para as demais etapas que resultaram em baixos níveis de produção. Assim sendo, a redução mínima de percentual obtido nesses resultados, poderá originar uma diminuição de suma importância no custo final das mudas produzidas.

Tabela 6 - Distribuição percentual dos custos operacionais por etapa de produção.

Table 6 - Percentage distribution of the operational costs per production stage.

\begin{tabular}{|c|c|c|c|c|c|c|c|c|}
\hline \multirow{2}{*}{ Item } & \multirow{2}{*}{ Despesas } & \multicolumn{6}{|c|}{ Composição percentual dos custos por etapa } & \multirow{2}{*}{$\begin{array}{c}\text { Composição \% } \\
\text { dos custos }\end{array}$} \\
\hline & & 1 & 2 & 3 & 4 & 5 & 6 & \\
\hline 1 & Mão-de-obra (salário) & 3,04 & 0,19 & 0,18 & 16,55 & 2,68 & 5,28 & 27,93 \\
\hline 2 & Encargos sociais & 1,05 & 0,07 & 0,06 & 5,70 & 0,92 & 1,82 & 9,61 \\
\hline 3 & Material de segurança & 2,48 & 0,15 & 0,15 & 13,49 & 2,18 & 4,30 & 22,75 \\
\hline 4 & Administração & 0,22 & 0,01 & 0,01 & 1,20 & 0,19 & 0,38 & 2,03 \\
\hline 5 & Depreciação & 1,00 & 0,06 & 0,06 & 5,43 & 0,88 & 1,73 & 9,16 \\
\hline 6 & Combustíveis & 0,52 & 0,03 & 0,03 & 2,85 & 0,46 & 0,91 & 4,82 \\
\hline 7 & Lubrificantes & 0,00 & 0,00 & 0,00 & 0,01 & 0,00 & 0,00 & 0,01 \\
\hline 8 & Pneus & 0,00 & 0,00 & 0,00 & 0,02 & 0,00 & 0,01 & 0,04 \\
\hline 9 & Fertilizantes & 0,56 & 0,03 & 0,03 & 3,02 & 0,49 & 0,96 & 5,10 \\
\hline 10 & Material de consumo & 1,45 & 0,09 & 0,09 & 7,88 & 1,27 & 2,51 & 13,29 \\
\hline 11 & Oficina própria & 0,00 & 0,00 & 0,00 & 0,01 & 0,00 & 0,00 & 0,02 \\
\hline 12 & Serviço de terceiros & 0,28 & 0,02 & 0,02 & 1,54 & 0,25 & 0,49 & 2,60 \\
\hline 13 & Energia elétrica & 0,14 & 0,01 & 0,01 & 0,77 & 0,12 & 0,24 & 1,29 \\
\hline \multirow[t]{2}{*}{14} & Outros & 0,15 & 0,01 & 0,01 & 0,79 & 0,13 & 0,25 & 1,34 \\
\hline & Total & 10,90 & 0,68 & 0,65 & 59,27 & 9,59 & 18,90 & 100,00 \\
\hline
\end{tabular}

Etapas de produção: 1 - Desinfecção de tubetes; 2 - Preparo do substrato; 3 - Enchimento de tubetes; 4 - Coleta de estacas e estaqueamento; 5 - Seleção e alternagem; 6 - Expedição de mudas.

Cerne, Lavras, v. 16, n. 3, p. 359-366, jul./set. 2010 
Tabela 7 - Custos de produção de mudas de eucalipto.

Table 7 - Production costs of eucalyptus seedlings.

\begin{tabular}{lcc}
\hline Etapas de produção & Custo de produção de mudas (US\$.mil-1) & Acumulado (\%) \\
\hline Coleta de estacas e estaqueamento & 77.63 & 59,28 \\
Expedição de mudas & 24.76 & 78,18 \\
Desinfecção de tubetes & 14.28 & 89,08 \\
Seleção e alternagem & 12.56 & 98,67 \\
Preparo do substrato & 0.89 & 99,35 \\
Enchimento de tubetes & 0.85 & 100,00 \\
\hline
\end{tabular}

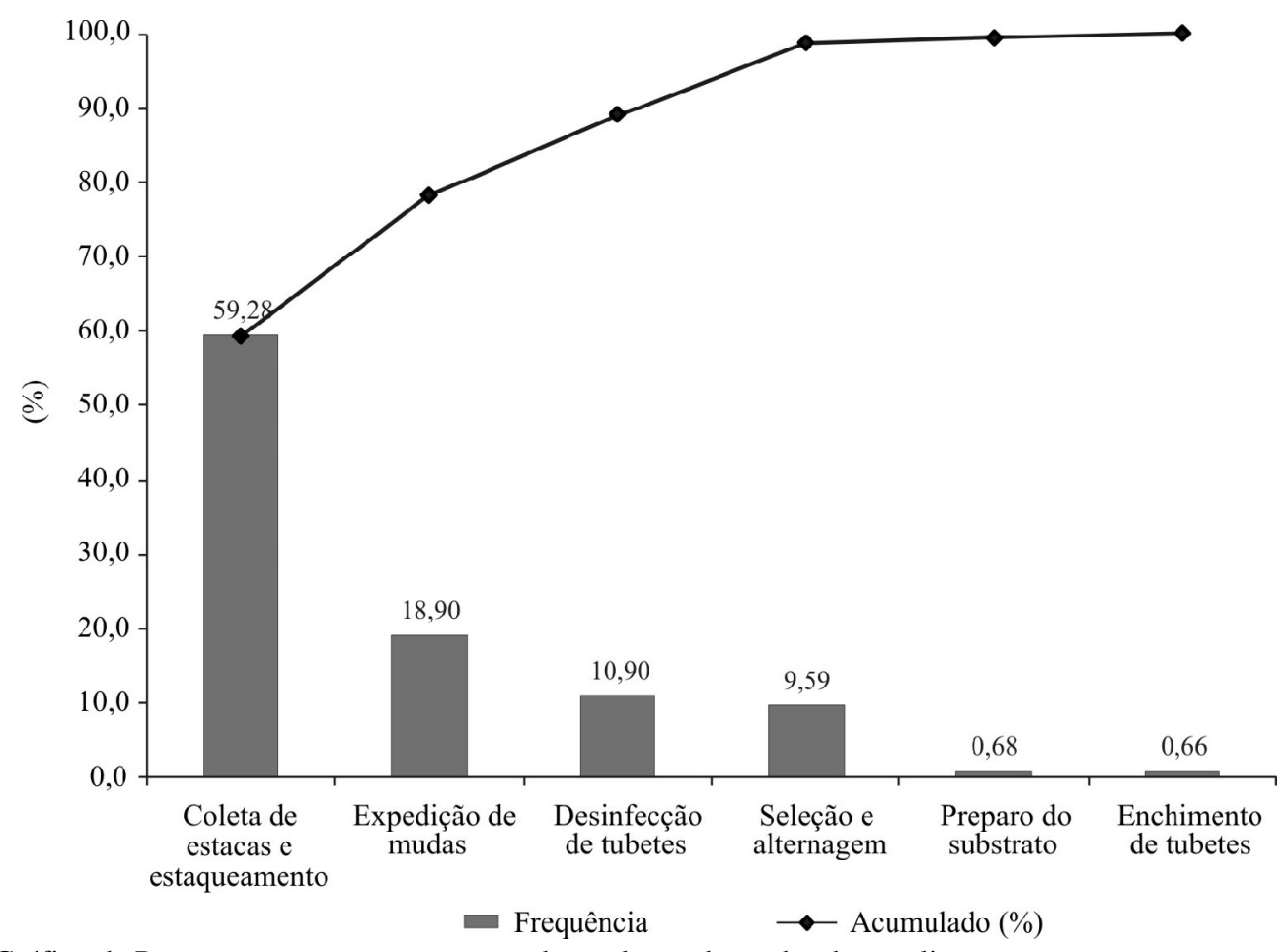

Figura 2 - Gráfico de Pareto para os custos por etapa de produção de mudas de eucalipto.

Figure 2-Pareto's chart for the costs per stage of eucalyptus seedling production.

\section{CONCLUSÕES}

As despesas com pessoal são as que mais oneram o custo final da produção de mudas de eucalipto, o que corrobora a necessidade do estudo de tempos e movimentos como ferramenta de auxílio para o dimensionamento adequado da mão-de-obra, o qual pode originar alterações na lucratividade.

Considerando a crescente demanda de mudas de eucalipto em um segmento cada vez mais competitivo, as empresas florestais necessitam administrar os coeficientes técnicos de cada etapa de produção, no sentido de estabelecer o valor ótimo da eficiência e do rendimento operacional, fatores esses determinantes para o gerenciamento da produção e competitividade.

\section{REFERÊNCIAS BIBLIOGRÁFICAS}

BARNES, R. M. Motion and time study: design and measurement of work. 6. ed. New York: J. Willey, 1968. 799 p.

Cerne, Lavras, v. 16, n. 3, p. 359-366, jul./set. 2010 
BARNES, R. M. Projeto e medida do trabalho. São Paulo: E. Blücher, 1977. 635 p.

BECKER, G. S. A theory of allocation of time. Economic Journal, v. 75, p. 493-517, 1965.

BRUZZI, D. G. Gerência de projetos: uma visão prática. São Paulo: Érica, 2002. 118 p.

CAMPINHOS, E.; IKEMORI, Y. K. Introdução de novas técnicas na produção de mudas de essências florestais. Silvicultura, v. 8, n. 28, p. 226-228, 1983.

DELWAULLE, J. C.; LAPLACE, Y.; QUILLET, G. Production massive de boutures d' Eucalyptus en République Populaire du Congo. Silvivultura, v. 8, n. 32, p. 779-781, 1983.

DINSMORE, P. C.; SILVEIRA NETO, F. H. Gerenciamento de projetos: como gerenciar seu projeto com qualidade, dentro do prazo e custos. Rio de Janeiro: Qualitymark, 2004. 176 p.

FREITAS, T. A. S.; BARROSO, D. G.; CARNEIRO, J. G. A.; PENCHEL, R. M.; FIGUEIREDO, F. A. M. M. Mudas de eucalipto produzidas a partir de miniestacas em diferentes recipientes e substratos. Revista Árvore, Viçosa, v. 30, n. 4, p. 519-528, 2006.

GONÇALVES, J. L. M.; POGGIANI, F. Substrato para produção de mudas florestais. In: SOLO-SUELO- CONGRESSO LATINO
AMERICANO DE CIÊNCIA DO SOLO, 13., 1996, Águas de Lindóia. Anais... Águas de Lindóia: SLCS; SBCS; ESALQ/USP; CEA-ESALQ/USP; SBM, 1996. CD-ROM.

HARRISON, A. J.; QUARMBY, D. A. The value of time. In: LAYARD, R. (Ed.). Cost-benefit analysis. London: Penguin, 1972. $496 \mathrm{p}$.

PENCHEL, R. M.; NEVES, D. C.; CAMPINHOS, C. N.; EVANGELISTA, A. L. DESCHAMPS, C. Otimização de parâmetros fisiológicos da propagação vegetativa por estaquia de matrizes elite de eucaliptos. In: CONGRESSO BRASILEIRO DE FISIOLOGIA VEGETAL, 5., 1995, Lavras. Anais... Lavras: SBFV, 1995.

REZENDE, J. L. P.; SILVA, M. L. Elaboração e avaliação de um projeto de produção de madeira de Pinus sp. na Região de Ubá. Viçosa, MG: SIF, 1997. 61 p. (Documento SIF, 15).

SILVA, M. L.; JACOVINE, L. A. G.; VALVERDE, S. R. Economia florestal. 2. ed. Viçosa, MG: UFV, 2005. 178 p.

STEINER, P. Choosing among alternative investment in the water-resource field. American Economic Review, Washington, v. 49, n. 5, p. 893-919, 1959.

XAVIER, A.; COMÉRIO, J. Microestaquia: uma maximização da micropropagação de Eucalyptus. Revista Árvore, Viçosa, v. 20, n. 1, p. 9-16, 1996. 